
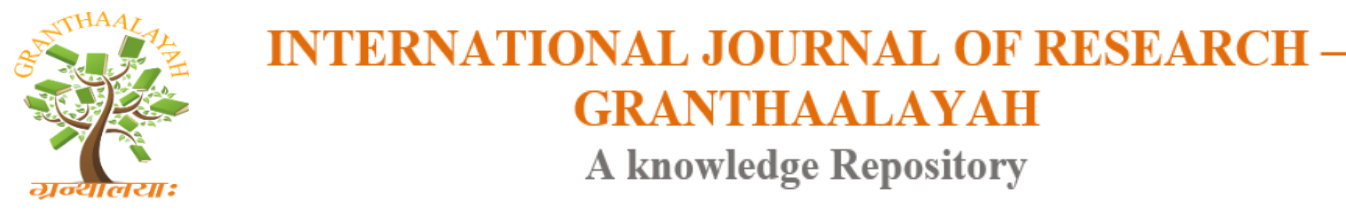

Social

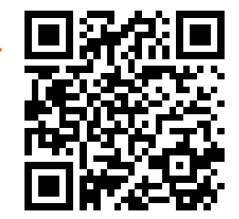

\title{
THE VIEWS OF PH.D. SAUDI STUDENTS AT THE UNIVERSITY OF GLASGOW TO UTILISE SOCIAL MEDIA TOOLS TO SUPPORT LEARNING
}

\author{
Omar Abdullah Alshehri *1 \\ ${ }^{* 1}$ Department, Collage: School of Education. University of Glasgow (UNITED KINGDOM)
}

\begin{abstract}
This paper examined the perception of using social media tools to support learning among Ph.D. Saudi students at the University of Glasgow. It also examined the benefits of using social media tools for learning and the important role that these tools can play to facilitate the educational process. Moreover, it examined the barriers they could face during the use of social media tools in the education process. Participants in this study were $3 \mathrm{Ph}$.D. Saudi students at the University of Glasgow. Semi-structured interviews were used to collect data for this study. The results indicate that students, both male and female, are using social media tools and their opinions largely coincide regarding the benefits of and barriers to social media usage. The results pointed out that the major barriers to using these tools in learning were a distraction, privacy, and the lack of available highspeed Internet. The study recommended that this study could be replicated at other Saudi Ph.D. students at different universities to investigate teachers and students' perception to use these modern technologies for learning as well as find out factors and barriers that might affect Saudi teachers and students' attitudes toward using social media tools for learning.
\end{abstract}

Keywords: Saudi Arabia; Social Media Tools; Advantages of Social Media Tools; Disadvantages of Social Media Tools.

Cite This Article: Omar Abdullah Alshehri. (2020). "THE VIEWS OF PH.D. SAUDI STUDENTS AT THE UNIVERSITY OF GLASGOW TO UTILISE SOCIAL MEDIA TOOLS TO SUPPORT LEARNING." International Journal of Research - Granthaalayah, 8(4), 1-6. https://doi.org/10.29121/granthaalayah.v8.i4.2020.24.

\section{Introduction}

The ubiquity of social media tools today cannot be ignored and there is a need to find a way to utilise these technologies for learning [1]. The classrooms today no more depend on the traditional methods that depend on one-way teaching and there is a call for a more personalized learning environment that integrates the new technologies instead of memorisation-based teaching style [2]. As opposed to traditional classes, social media tools have opened up numerous paths and horizons for learners to acquire knowledge and share information. Moreover, these tools allow learners to create their own content and have control over communication and distribution which 
ultimately makes the student to be at the very center of learning activities, thus creating a real student-centred learning environment possible [3]. The role of the learners in this era with these tools became more active and participatory: the learners are not simply consumers of materials, which have been compiled by instructors (4). Therefore, this paper examined the perception of using social media tools to support learning among Ph.D. Saudi students at the University of Glasgow, the benefits of using social media tools for learning and the important role that these tools can play to facilitate the educational process, and the barriers they could face during the use of social media tools in the education process.

Ref. [9] define social media as "a group of Internet-based applications that build on the ideological and technological foundations of web 2.0 and that allow the creation and exchange of usergenerated content. It is a medium for social interaction as a super-set beyond social communication enabled by ubiquitously accessible and scalable communication techniques" (p. 63). These technologies include a variety of networked tools that emphasize the social aspects of the Internet as a channel for communication, collaboration, and creative expressions such as Facebook, Twitter, YouTube, WhatsApp, Wikipedia, and Skype.

Social media tools have received a great deal of recent attention for their potential to facilitate and enhance learning [11]. It has been argued that they are transforming the ways instructors communicate, collaborate and teach.

"Social connections affect so many aspects of our lives that our argument that they can also be applied to education and learning should be no surprise" [10].

At an internal level, social media statistics reveal that the number of internet users in Saudi Arabia rose swiftly to 30 million people by the beginning of 2018. It is estimated that on average, Saudi residents spend roughly five hours per day using social media, making it one of the largest social media markets in the Middle East. Social media tools are beginning to play an important role in the lives of Saudi Arabians and its usage has expanded rapidly. Out of nearly 25 million total active users on social media, 18 million access these tools through their mobile devices. This number accounts for nearly $72 \%$ of all social media users in the country [13].

In the field of education, Ref. [3] studied the usage of the most popular social media tools, such as Facebook, Twitter, Instagram, and WhatsApp, in a number of major universities in Saudi Arabia. The results revealed that the use of social media tools is quite prevalent among major universities in Saudi Arabia, although the usage of these tools seems to remain under-utilised by Saudi students. Likewise, Ref. [1) emphasised in her study that Facebook, Wikipedia, and YouTube are the top three social media tools most used as a learning resource because they bring social engagement, communication, the speed of feedback and relationship building. Ref. [12] argued that relationships formed via social media tools between university tutors and students open up new avenues of communication and result in an enhanced learning environment.

In a qualitative study, [13] found that teachers felt social media made their classrooms more interactive and allowed their students more quality opportunities to communicate and collaborate and improve teacher-to-student communication. Likewise, Ref. [10] added that using social media tools, such as Facebook, builds strong relationships among tutors and students and helps develop 
self-confidence. It also enhances direct communication, thereby increasing the speed of feedback, while supporting students and facilitating learning among peers. Additionally, Ref. [8] found that $60 \%$ of their 137-participant sample felt that social media would improve student-to-teacher interactions. Moreover, at a University in Saudi Arabia, Ref. [5\} conducted a quantitative study involved 308 participants to examine the use of social media tools and their impact on knowledge sharing and learning performance by tertiary students. The results of the study imply that the use of social media tools for chatting and discussion and for file sharing is becoming common among university teachers and students, and this positively affects knowledge sharing and impact student learning to improve their learning.

However, social media tools have different challenges. Ref. [7] observed that online networking use could cause security concerns as well as protection and integrity. Other privacy issues related to the use of SM is students' lack of care with the information they post on social media tools (2). In another investigation carried out in the context of Saudi society, Ref. [3] conducted a study to examine the use of SM sites in KSA. The results of the study indicated that privacy and security concerns continue to be the biggest challenges inhibiting the usage of SM applications, particularly by female students.

Another issue related to the use of SM is distractions. Ref. [9] report that using social media for learning distract learners from focusing on the course content. They also found that students do not take the integration of social media tools into the learning environments seriously. Moreover, Ref. [4] conducted a study at KKU in KSA to explore the views of 160 male students regarding the advantages and limitations of using social media tools. The researchers found that " $48 \%$ of the students mentioned technical and Internet problems as the major challenge to their successful learning via these tools" [4].

\section{Materials and Methods}

The purpose of the interviews was to examine the perception of using social media tools to support learning among Ph.D. Saudi students at the University of Glasgow, the benefits of using social media tools for learning and the important role that these tools can play to facilitate the educational process, and the barriers they could face during the use of social media tools in the education process. The sample of this study was 2 males and 1 female Ph.D. Saudi students from the College of Education at the University of Glasgow. The interviews sought more in-depth data about the benefits of using social media tools for learning and the important role that these tools can play to facilitate the educational process, and the barriers they could face during the use of social media tools in the education process.

The qualitative data in this research was obtained from semi-structured interviews. Thematic analysis was applied to this qualitative data. The interviews data was coded and analysed through adapting the framework of [3] which stated that "In different texts, the approaches to analysis of qualitative data vary slightly, but we believe they can be described in three stages (1) organizing and familiarising (2) coding, and (3) interpretation of the data" (p.481). A total of two broad themes emerged during the process of analysis of interviewee's responses and data collected from the interviews. The themes that emerged included (a) the benefits of using social media tools for 
learning and the important role that these tools can play to facilitate the educational process, and (b) the barriers they could face during the use of social media tools in the education process.

\section{Results and Discussions}

\subsection{The Advantages of Using Social Media Tools for Learning}

Analysing qualitative data collected has shown that the participants have positive perceptions towards using social media tools for learning despite they indicated some concerns to integrate these platforms in education. The participants reported their desire to use social media in all the courses they teach or study. As a matter of fact, when one of the participants was asked if he prefers using social media in learning, he said: "social media are the tools of the current era that the learners cannot ignore them" (Respondent: 1). Another participant declared in the interview that "she used these tools to facilitate earning information from different resources" (Respondent: 3 ). This finding is not new to research in this field as Ref. [5] found that the perceived usefulness and ease of use of social media platforms will affect attitudes towards its use.

Furthermore, the interviews data analysis revealed that social media platforms are effective for building participation, interaction, collaboration, and communication among students and instructors. The participants stated that these tools can work to extend the opportunity for learners to contact their teachers whether in classes or beyond formal sessions. A participant at the interviews explained that "social media tools provide a great channel to interact between teachers and students to ask questions or discuss subjects related to lessons to increase the engagements and extend conversations" (Respondent: 2). Ref. [6] emphasised the potential of social media sites to increase interaction and networking between teachers and students as well as to co-create content in and out of the classroom.

During the interviews, participants reported that they use social media to communicate with other teachers, students, and friends. For instance, participants 1 and 2 use WhatsApp App to connect with their students and receive their questions and homework. In a similar way, participant 3 pointed out that social media tools had made learning "faster and easier to communicate, to learn, and to teach". Moreover, all participants agreed that social media tools give students and teachers a lot of options and flexibility in how to present themselves and in how to interact with a learning activity set up by teachers or students. Undoubtedly using social media as e-learning tools will increase the chance of creating learners with many skills such as develop ideas, making arguments, exchanging opinions, and developing critical thinking. This is in line with the studies of [2], [3], [4], [10], [12], [13] that indicated that Twitter, WhatsApp, and YouTube were by far the most used social media tools for instructional sharing by teachers and students.

\subsection{The Disadvantages Related to The Use of Social Media Tools for Learning}

Participants noted that potential impediments to using social media tools for learning that are currently preventing teachers and students from engaging to a greater extent with each other through these tools. These concerns include distraction, privacy, and the lack of available highspeed Internet. All participants mentioned that learners can be easily distracted from lessons when they use social media tools during classes to watch videos on YouTube or browse messages on 
Twitter, Facebook, and WhatsApp and use them for unintended purposes such as to play games and chat with friends. As the participant (3) stated, "some learners do not respect the role of using these tools inside the classrooms that may be misused and lead to distraction during lessons". This finding seems to be consistent with other studies (e.g. Ref.1 and 2), which found that one factor that discourages using SM in teaching environments is the distractions they pose to students which prevent learners from focusing on the course content.

Privacy was found also to be an important barrier that limits teachers and students to use social media tools for learning. The participants in this research reported concerns about the privacy and security issues related to social media tools used in the classrooms. They stressed the need to protect their privacy, or at the least, felt they should be made aware of the consequences of posting personal information by being offered workshops by the university to assist them to use those tools wisely. Participants 1 and 2 revealed that users should receive enough training about the right way to use these tools that maintain their privacy and prevent them from cyber-bullying. This result is consistent with the findings of the study by Ref. [3] that pointed out that privacy and security concerns continue to be the biggest challenges inhibiting the usage of social media tools for learning, particularly among female students.

\section{Conclusions and Recommendations}

Semi-Structured interviews were used to collect results obtain from 2 males and 1female Ph.D. Saudi students at the University of Glasgow. This study examined the perception of using social media tools to support learning among $\mathrm{Ph}$.D. Saudi students at the University of Glasgow. It also examined the benefits of using social media tools for learning and the important role that these tools can play to facilitate the educational process. Moreover, it examined the barriers they could face during the use of social media tools in the education process. Thematic analysis was applied to this qualitative data. Results indicated that some of the interviewees had very positive attitudes towards using social media as tools for e-learning and felt that these tools were extremely effective instructional tools and should be integrated into the university curricula and that teachers and students should start using them as tools to aid the other learning environments. However, the results indicated that the major barriers to using these tools in learning were a distraction, privacy, and the lack of available high-speed Internet. In addition, investigating other Saudi Ph.D. students to study factors and barriers that might affect Saudi students' attitudes toward using social media to support learning is valuable. Use as many sections/subsections as you need.

\section{Acknowledgements}

Firstly, I would like to express my sincere gratitude to my supervisor Prof. Vic Lally who provided insight and expertise that greatly assisted to write this paper. I am using this opportunity to express my gratitude to my colleagues at the University of Glasgow who supported me during the write of this paper. I am thankful for their aspiring guidance, invaluably constructive criticism and friendly advice during writing this paper.

\section{References}

[1] Aifan, H.A. (2016) Usage of Social Media Technologies by Saudi Instructors at King Abdul-Aziz University to Support Students' Learning., 5 (6), pp.74-76. 
[2] Alshehri, O., Lally, V. (2019). 'Students' Perceptions of the Use of Social Media in Higher Education in Saudi Arabia. World Academy of Science, Engineering and Technology, International Science Index 145, International Journal of Social, Behavioral, Educational, Economic, Business and Industrial Engineering, 13(1), 28 - 31.

[3] Alsurehi, H. A., \& Youbi, A. A. A. (2014). Towards applying social networking in Higher Education: Case study of Saudi Universities. International Journal of Academic Research, 6(5), 221-229.

[4] Al Zumor, A., Al Refaai, I., Eddin, E., \& Al-Rahman, F. (2013). EFL Students' Perceptions of a Blended Learning Environment: Advantages, Limitations and Suggestions for Improvement. English Language Teaching, 6(10), 95.

[5] Basu, B. (2017). Analyzing the Perception of Social Networking Sites as a Learning Tool among University Students: Case Study of a Business School in India. International Journal of Educational and Pedagogical Sciences, 11(7), 1697-1703.

[6] Dabbagh, N., \& Kitsantas, A. (2013). The role of social media in self-regulated learning. International Journal of Web Based Communities, 9(2), 256-273.

[7] Devine, L. \& Parker, S. (2015) Rethinking Child Protection Strategy: Learning from Trends.

[8] Hashim, K., Al-Sharqi, L., \& Kutbi, I. (2019). Perceptions of Social Media Impact on the social behavior of students: A comparison between students and faculty. In Multigenerational Online Behavior and Media Use: Concepts, Methodologies, Tools, and Applications (pp. 92-103). IGI Global

[9] Kaplan, A.M. and Haenlein, M. (2010), "Users of the world, unite! The challenges and opportunities of social media", Business Horizons, Vol. 53 No. 1, pp. 59-68.

[10] King, G., and Sen, M. (2013) The Teacher: How Social Science Research Can Improve Teaching American Political Science Association, PS: Political Science and Politics 46, no. (3) (pp 621-629)

[11] Lee, J., Lee, Y., \& Kim, M. H. (2015). Perceptions of teachers and students towards the educational application of SNS and its educational effects in middle school class. Turkish Online Journal of Educational Technology, 14(4), 124-134.

[12] Liu, Y. (2010). Social media tools as a learning resource. Journal of Educational Technology Development and Exchange, 3(1), 101e114.

[13] Salem, F. (2017). Social media and the internet of things towards data-driven policymaking in the Arab world: potential, limits and concerns. The Arab Social Media Report, Dubai: MBR School of Government, 7.

*Corresponding author.

E-mail address: o.alshehri.1@ research.gla.ac.uk 